On the Coherence between Dynamics of the World Fuel Consumption and Global Temperature Anomaly

$$
\text { by }
$$

L.B. Klyashtorin \& A.A. Lyubushin

\author{
Reprinted from \\ ENERGY \& \\ ENVIRONMENT \\ VOLUME 14 No. 62003
}

MULTI-SCIENCE PUBLISHING CO. LTD.

5 Wates Way, Brentwood, Essex CM 15 9TB, United Kingdom 


\title{
ON THE COHERENCE BETWEEN DYNAMICS OF THE WORLD FUEL CONSUMPTION AND GLOBAL TEMPERATURE ANOMALY
}

\author{
L.B. Klyashtorin ${ }^{1}$ \\ Federal Institute for Fisheries and Oceanography (VNIRO), 107140 Moscow, B. \\ Krasnoselskaya,17.Russia.Email: klyashtorin@mtu-net.ru
}

A.A. Lyubushin

Institute of the Physics of the Earth, Russian Academy of Sciences, Moscow, Russia.

\begin{abstract}
Analysis of the long-term dynamics of World Fuel Consumption (WFC) and the Global Temperature anomaly (dT) for the last 140 years (1961-2000) shows that unlike the monotonously and exponentially increasing WFC, the dynamics of global dT against the background of a linear, age-long trend, undergo quasi-cyclic fluctuations with about 60 a year period. No true linear correlation has taken place between the dT and WFC dynamics in the last century.

Spectral analysis of reconstructed temperature for the last 1420 years and instrumentally measured for the last 140 years global dT shows that dominant period for its variations for the last 1000 years lies in the 50-60 years interval.

Modeling of roughly 60 -years cyclic dT changes suggest that the observed rise of dT will flatten in the next 5-10 years, and that we might expect a lowering of dT by nearly $1-0.15^{\circ} \mathrm{C}$ to the end of the $2020 \mathrm{~s}$.
\end{abstract}

Keywords: global warming, fuel consumption, global climate variations, spectral analysis, time-frequency analysis.

\section{BACKGROUND}

Development of the world energy status is directly attributed to the consumption of fossil fuel (oil, gas, and coal). Resulting in the large-scale atmospheric emission of carbon dioxide and some other so-called "greenhouse" gases, which are known to hinder the Earth thermal irradiation to outer space, i.e., affect the normal temperature balance on the planet. The infrared irradiation absorbed by the earth's atmosphere is believed to cause gradual increase in the surface air temperature at the global scale. This phenomenon is known as "Global Warming" and has variable (mainly negative) consequences (Schneider, 1990, 1992, IPPC, 1990, 1996, 2001).

$\overline{1 \text { corresponding author }}$ 
The purpose of this work is to provide a comparative analysis of general dynamics of Global temperature anomaly (dT) changes and World Fuel Consumption (WFC) for the entire period of instrumental measurements (140 years, since 1861 to the present).

The main index of climate change on the global scale is the Global dT, time series of measured instrumentally for the last 140 years. Annual values of Global dT are very variable, and a reliable climatic trend can be revealed only after a considerable smoothing of the time series.

We use time series of land and sea air surface Global temperature anomaly (dT) from published sources (i.e. Bell et al., 2000, Lawrimor et al., 2001 and Jones et al., 1999, 2001) (http://www.cru.uea.ac.uk)

World Fuel Consumption (WFC) for the period 1850-1996 expressed in "tons of nominal fuel" taken from Makarov (1998) and update to 2000 - via personal communication of author (Institute of Energetic Problems, Russian Academy of Sciences). Time series of annual air surface temperature for the last 1420 years reconstructed by analyzing heavy isotope of oxygen $\left(\mathrm{O}^{18}\right)$ from Ice Cores of Greenland Ice Sheet was kindly provided by Geophysical Isotope Laboratory University of Copenhagen, Denmark through Dr. V.I. Nikolaev (Institute of Geography Russian Academy of Sciences)

\section{RESULTS AND DISCUSSION}

Since the middle of the $19^{\text {th }}$ century, the WFC curve exhibits roughly exponential virtually permanent growth at a rate of about $2.3 \%$ per year, i.e., roughly doubling every 30 years (Figure 1). Total WFC in the middle of $19^{\text {th }}$ century was as low as 550 million tons, and by the late $20^{\text {th }}$ century this value increase by a factor of 25 .

The dT curve has the age-long linear trend increasing by $+0.059^{\circ} \mathrm{C}$ every 10 years. By the end of $20^{\text {th }}$ century, the global dT increased by $0.6-0.8^{\circ} \mathrm{C}$ compared to the early $20^{\text {th }}$ century (Sonechkin, 1998). The WFC and global dT dynamics have two key differences as follows:

1) The age-long increase in WFC is approximated by an exponent, while the agelong increase in global dT exhibits a linear trend.

2) Unlike monotonously and exponentially increasing WFC, the dynamics of global dT with the background of a linear, age-long trend undergoes quasi-cyclic fluctuations with a period about 60 years. (Figure 1).

Each of the observed dT cycles could be divided in two 20-30-year phases of ascending or descending smoothed dT curve. Relationship of dT and WFC dynamics in each of these phases are presented in the Table. 


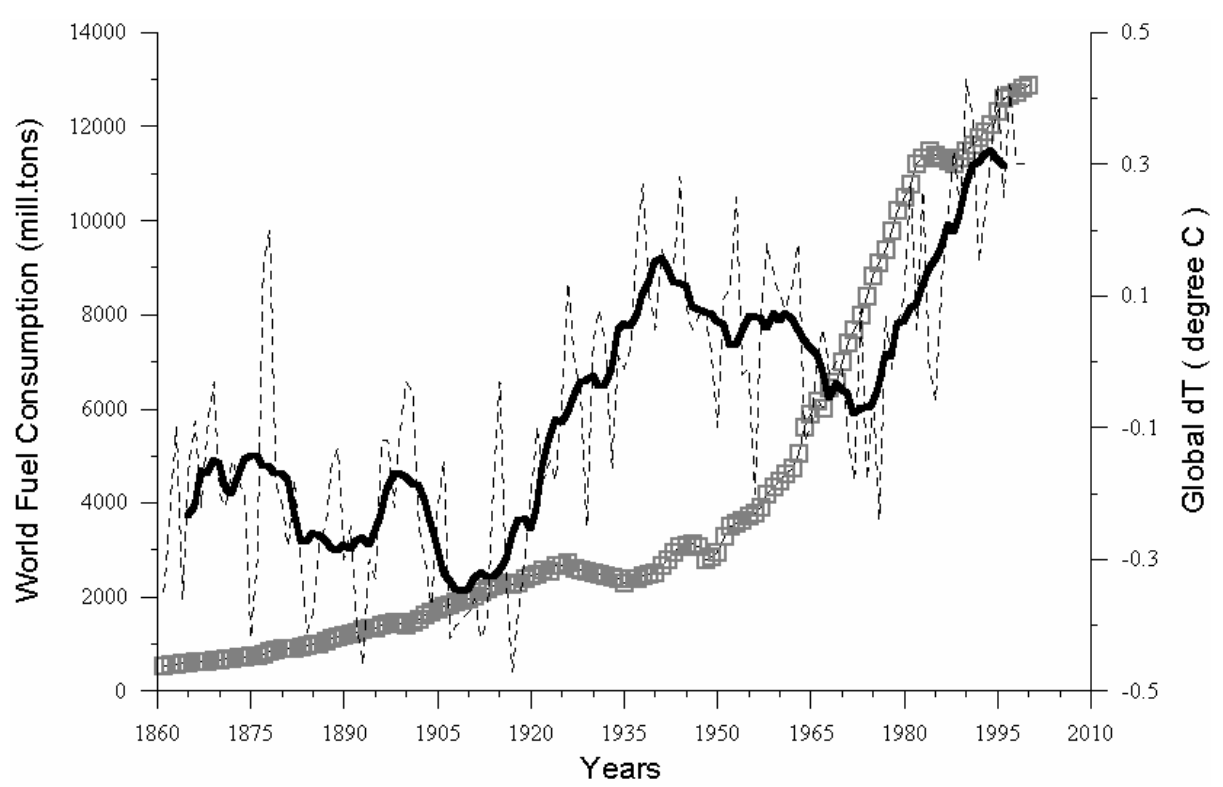

Figure 1. Comparative dynamics of the World Fuel Consumption (WFC) and Global Temperature Anomaly (dT) 1861-2000. Thin line - annual dT; Bold line 13-years smoothing; Dashed line - WFC (mill. tons of nominal fuel).

Table. Correlation between Global dT and World Fuel Consumption (WFC) in the different time phases of the 1860-2000s.

\begin{tabular}{ccc}
$\begin{array}{c}\text { Phase of changing } \\
\text { Global dT }\end{array}$ & $\begin{array}{c}\text { Period of Observation } \\
\text { (years) }\end{array}$ & $\begin{array}{c}\text { Correlation Coefficient } \\
\text { Between dT and WFC }\end{array}$ \\
\hline Ascending & $1861-1875$ & +0.92 \\
Descending & $1875-1910$ & -0.71 \\
Ascending & $1910-1940$ & +0.28 \\
Descending & $1940-1975$ & -0.88 \\
Ascending & $1975-2000$ & +0.94 \\
Descending (?) & $2000-2030$ & $?$
\end{tabular}

Between 1861-1875, both WFC and dT exhibited simultaneous, well-correlated growth. During 1875-1910, the dynamics of these indices were different. WFC continues to grow, while global dT decreases, which reflects in negative correlation between the indices. The next period, from 1910 to 1940, is of particular interest in this context. For these 30 years WFC shows virtually no increase because of the global economic crisis of 1920-30-s. However, dT in the same period increased by more than $0.4^{\circ}$. During the subsequent 35-years (1940-1975), WFC increased by a factor of 2.5 (from 3 to 7 billion tons.). For the same period, global dT did not increase, but decreased roughly by $0.12^{\circ} \mathrm{C}$ and negative correlation between the WFC and dT dynamics is characteristic of this time period. 
In the recent 25-year period (1975-2000), in accordance with the ascending phase of an alternate dT fluctuation (see Figure 1 and Table 1), a close positive correlation takes place between the dynamics of WFC and dT.

Thus, on the background of monotonous increase in WFC during the last 140 years, global dT dynamics exhibited alternating 25-30-year periods of lowering or raising (with the corresponding alternation of positive or negative correlation between the WFC and dT trends).

What changes in the dynamics of WFC and Global dT can we expect in the near future, between 2000-2030?

Proceeding from the hypothesis of cyclic dynamics of global dT with a period of 50-60 years, we assume that the current "increasing" phase started in 1975 reached its maximum by 2000, then the gradual decrease in $\mathrm{dT}$ will start in the nearest few years and continue up to the 2030 s.

It should be mentioned that the 50-60-year period of the dT fluctuations has been derived from the time series of the instrumentally measured temperatures for the last 140 years "by eye" (Figure 1). This time period includes only 2.5 roughly 60 -year cycles, and it is insufficient from an analytical perspective for a statistically rigorous conclusion on the cyclic character of the fluctuations and analysis of much longer time series required.

However, polar glaciers contain paleo-climatic information in the form of the isotopic composition of the oxygen as described by deviation of the heavy oxygen isotope $\mathrm{O}^{18}$ concentration in the ice from that of Standard Mean Ocean Water. The most suitable location to perform global paleo-temperature reconstruction using this method is the central region of the Greenland ice sheet, where the conditions for snow and ice accumulation are believed to have remained stable over the last 2000 years. ("Nowhere else in the world is it possible to find a better combination of a reasonable high accumulation rate, simple ice flow pattern, high ice thickness and meteorologically significant location close to the main track of North Atlantic cyclones" (Dansgaard et al., 1975).

Ice drilling undertaken by the joint American-Danish-Swiss expedition in the 1970s resulted in obtaining intact ice cores to the depth of $404 \mathrm{~m}$. Average thickness of the annual ice layers in this region of Greenland is about $30 \mathrm{~cm}$, which made it possible to reconstruct the annual average temperatures for the last 1500 years with high accuracy. Reconstruction of temperature in the ice cores is based on the so-called "isotopic effect". Some proportion of water molecules are known to contain heavy oxygen isotope $\mathrm{O}^{18}$ instead of "usual" $\mathrm{O}^{16}$. These molecules are about $9 \%$ heavier compared to common molecules and evaporate somewhat slower. Therefore, the proportion of heavy molecules in water vapor is lower than in oceanic water, but increases as the temperature increases. Water evaporated from the vast surface of the North Atlantic was transferred by the atmospheric streams into the Greenland region where precipitated as snow and then turned into ice layers. Concentrations of heavy isotopes $\mathrm{O}^{18}$ in the ice specimens can be determined with a high accuracy using the mass-spectrometry.

The time series of instrumentally measured (1861-2000) and reconstructed (5541974) temperature overlap for 113 years giving us an opportunity to compare results of reconstructed and instrumental data of temperature changes (Fig 2). 


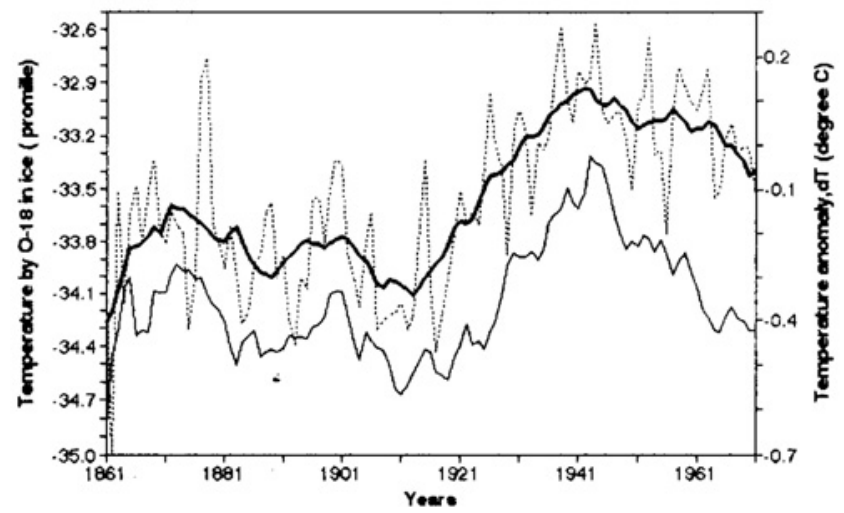

Figure 2. Comparative dynamics of instrumentally measured global temperature anomaly (dT) and reconstructed (by $\mathrm{O}^{18}$ in Greenland Ice Cores) temperature for period of 1861-1973 years. Dashed line - annual Global dT values; Bold line - the same smoothed by 13-years averaging; Thin line - smoothed by 15 years averaging annual reconstructed temperature.

As one can see the smoothed temperature curves reconstructed from $\mathrm{O}^{18}$ Greenland Ice Cores temperature and Global dT practically coincide, confirming that reconstructed Ice Cores temperature series reflect similar series of Global dT very accurately.

The 10-years averaged temperatures reconstructed from the $\mathrm{O}^{18}$ concentration in the Greenland ice cores and spectral characteristics of the corresponding time series are presented in Figure 3(a.).

One can see that the relatively abrupt increase of global temperatures observed in the early 20th century is not unique event. Similar and possibly even more distinct temperature increases were observed in 500-900 years, the epoch of very mild climate in Atlantic-European region when Norsemen colonized Iceland and Greenland. (Dansgaard et al., 1975).
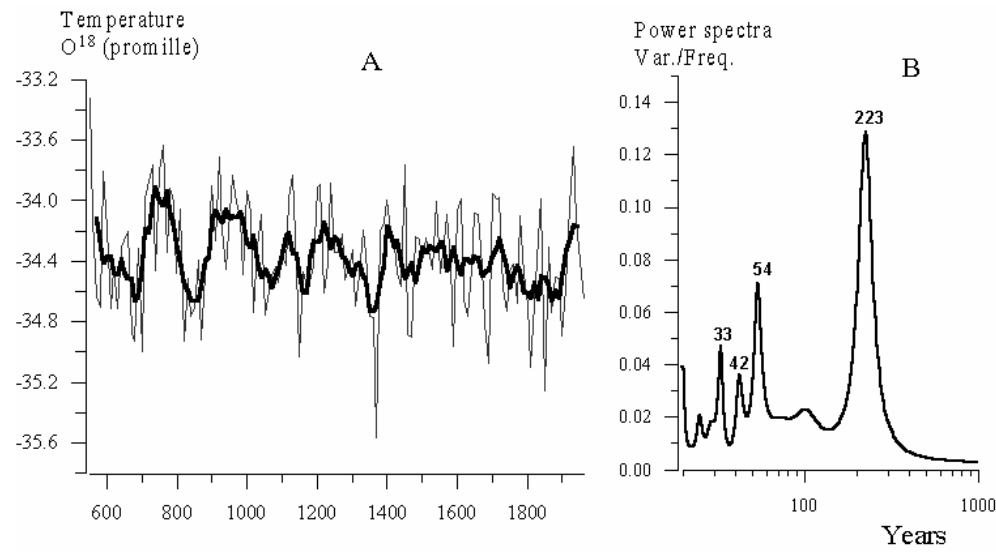

Figure 3. Reconstructed by $\mathrm{O}^{18}$ in Ice Cores temperature (a) and its power spectra (b) a) thin line: 10-years smoothed annual Ice Core temperature. bold line: the same smoothed 50 years moving window b) power spectra reconstructed temperature. 
The estimate of the power spectra of the time series on Fig3(b) shows clear peaks on periods 33, 42, 54 and 223 years. The spectral estimate was made for 10-years averaged lime series of reconstructed temperature (having 144 samples) by Burg's method of maximum entropy with auto-regression order 20 (Marple (Jr.), 1987)

However this spectral estimate is static, obtained by information from all time series at once and it is of special interest how this spectral maxima are distributed in time. Results of analysis of temporal dynamics of reconstructed temperature by Greenland Ice Cores are presented in Figure 4.

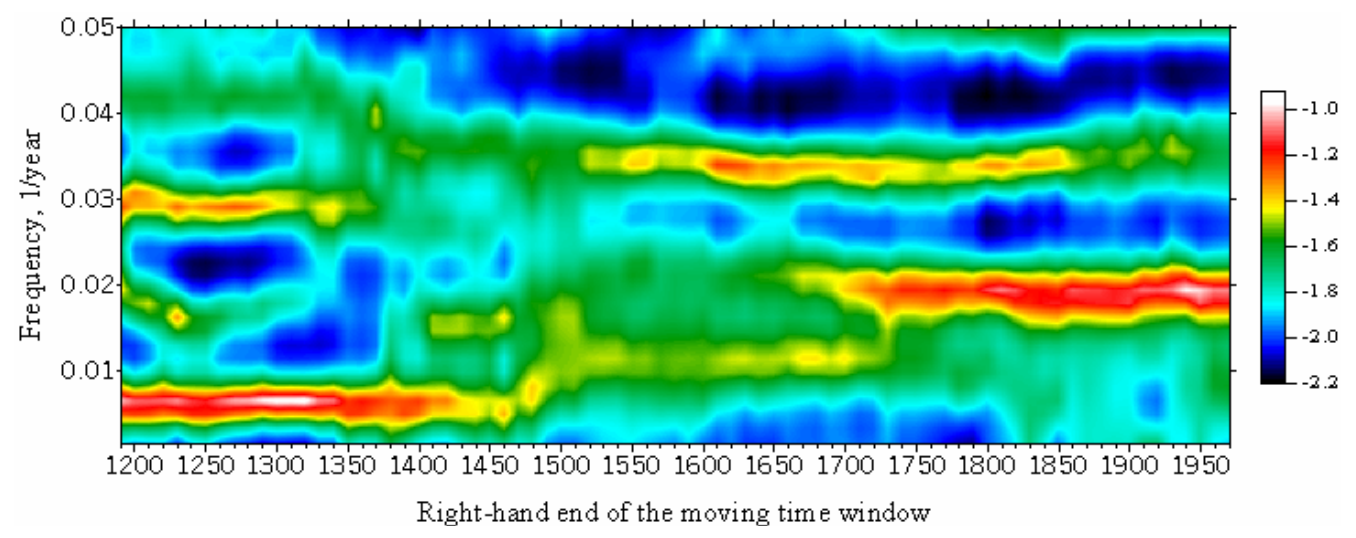

Figure 4. Temporal dynamics of the power spectra of temperature reconstructed from Greenland Ice Cores for time period 553-1973 years AD. Power estimates were obtained in the time window of the length 640 years. Decimal logarithmic scale for power spectra is used.

We have taken sixty-four ten year time-window readings (representing 640 years), and made spectral estimates of maximum entropy with AR-order 10. It should be understood that the time marks on the diagram on Figure 4 correspond to right side of time window.

To evaluate power spectra dynamics of in time, using a moving time-window, it is noticed that the low-frequency rhythm with period about 200 years occurs at the initial interval of time series only - between 550AD and 1400AD. Thereafter it disappears, but in Figure 3(b) it is present as a peak with period 223 years. Further, from 1100 until the late 1900s the spectral peak at a frequency of 50-60 years is dominant, and for the last 400 years the recurrence of this periodicity especially well expressed (Figure 4). The most recent modes of behavior of global dT are characterized by intensive harmonics with periods 50-60 years.

\section{EVALUATION OF CYCLIC CHANGE OF GLOBAL DT FOR THE LAST 140 YEARS AND APPROACHES TO PREDICTION.}

To evaluate the main regularities of evolution global dT for the last 140 years it is necessary to consider general linear trend, within the background of these 50-60 years and higher-frequency fluctuations with small amplitudes. These observations provide a basis for the prediction of behavior of low-frequency variations of global dT for the near-future decadal lime intervals. Let's select it length equal to 30 years (approximately half of period of the dominant harmonic). First, we evaluate parameters 
of the linear trend for the last 140 years and then subtract them from an analyzed time series of dT. From residual (after subtraction of linear trend) we then fit the best harmonics with some period ((our dominant cyclic trend) and finally, we calculate its values for the time period 2000-2030. When this is done, we return the eliminated general linear trend to the whole. The standard deviation of the residual after subtraction of linear and cyclical trends will set the intervals of errors of the forecast.

In this sequence of operations the main problem is a choice of period $\tau$ of a cyclic trend. It would be possible to put it equal to 54 years, as follows from Figure 3(b). But it is necessary to take into account that this value of a period is a result of averaging of the contributions of harmonics for all period of observations, i.e. for 1500 years. At the same time, as it can be seen in Figure 4, the spectral structure is rather non- stationary. As we are interested in the prediction for only a rather short interval of time (30 years), it is more logical to select a value of $\tau$ which in the best way reflects cyclic dynamics of dT just for recent (1861-2000) period of instrumental observations.

For a determination of $\tau$ the following approach was used. We set some interval of probe values of $\tau$. It is possible to find harmonics for each period of a cyclic trend from this long time interval. The best way is through fitting variations of dT after removing of general linear trend. The residual after removal of a cyclic trend with a given period will be characterized by some standard deviation dependent on values for the entire period. We then select period $\tau$ by setting the condition of using the period with the minimum within the standard deviation of residuals. The best value $\tau=64.13$ years was found, for the dT time series after removing the general linear trend and searching for $\tau$ in an interval of values between 20-200 years. This value lies well within the limits of the frequency band of dominating roughly 60-years harmonics of Greenland Ice Cores reconstructed temperature at least for the last 1000 years (Figure 4.)

The results of using the above method of $\mathrm{dT}$ trend prediction for $\tau=64.13$ years is presented in Figure 5.

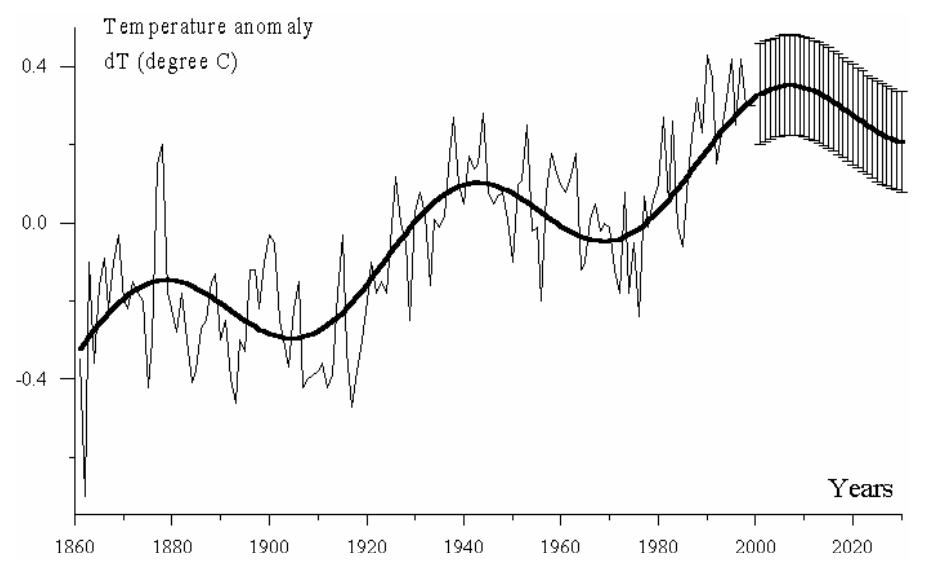

Figure 5. The dynamics of instrumentally measured and modeled Global dT trend, 1861-2030s Thin line - annual global dT; Bold line - cyclic modeled trend with period of 64.13 years; bold line with error bars - modeled predicted trend for 2000-2030s 
The bold line with vertical bars of standard deviations is the forecast of a lowfrequency behaviour of global dT for the next 30 years, is represented in Figure 5 by a thin black line. The bold line presents values of a cyclic trend for the interval of instrumental observations.

Thus, this model indicates that the maximum of the average value of global dT will level off in the next 5-10 years. Subsequently, one can expect a lowering of its value roughly by $0.1-0.15^{\circ} \mathrm{C}$ until the end of the $2020 \mathrm{~s}$.

The simultaneous increases of global dT and WFC trends in the last 1975-2000s period might well be the result of cyclic roughly 60 -year oscillations of global dT and alternating positive or negative correlation between phases of WFC and dT runs as observed in the past 140 years period of instrumental observations. The ongoing alternative phase period 2000-2030s as one might expect should be characterized by negative correlation between dT and WFC run (Figure 1, Table)

\section{ESTIMATING CONNECTION BETWEEN DT AND WSC BY THE "BLACK BOX" MODEL.}

For additional confirmation of our suggestion of independence variations of dT on WFC global fuel consumption the following evaluation was made.

We consider a global climatic system as a "black box", to which the annual increments of global consumption of fuel are added, with an output of annual increments of global dT. We have estimated linear frequency transfer properties of this "black box", namely, the squared module of a spectrum of coherence and an amplitude-frequency transfer function, using standard techniques of time-series processing (Brillinger, 1975; Marple(Jr.),1987), by averaging periodograms and crossperiodograms. For the length of time series 140 samples we obtained 128 frequency values. We then perform a rather deep (for such length of time series) averaging by the moving frequency window of a radius 10 frequency values. The result of such data processing is presented in Figure 6(a,b).
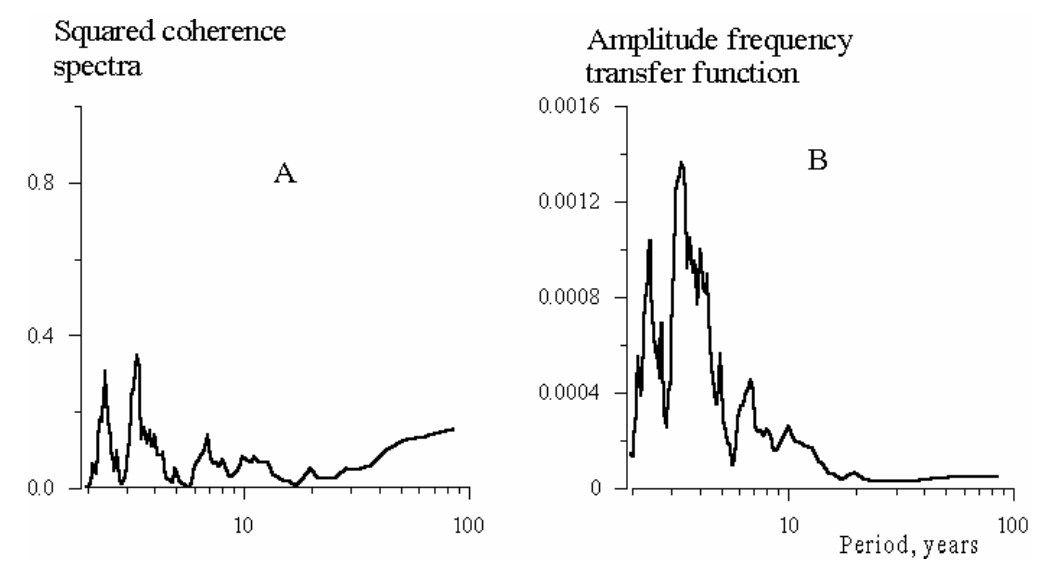

Figure 6. (a) Squared coherence spectra estimate between annual increments of WFC and annual increments of Global dT (b) Estimate of amplitude frequency transfer function from annual increments of WFC to annual increments of Global dT. 
As shown in Figure 6, some relationship exists within main variations with periods of less than 10 years, but this is extremely insignificant as from the point of view of squared coherence (Fig 6(a)) and from the value of response (Figure 6(b)), providing independent confirmation of the suppositions made at the beginning of "Results and discussion"

\section{CONCLUSION}

Unlike the monotonously and exponentially increasing of WFC, the dynamics of global dT against the background of an age-long linear trend, undergo quasi-cyclic fluctuations with a period about 60 years.

No true linear correlation exists between the Global dT and WFC dynamics for the last 140 years.

Spectral analysis of reconstructed temperature for the last 1400 years and instrumentally measured (for the last 140 years) global temperature anomaly dT shows cyclic 50-60 year variations for the last 1000 years.

Modeling of roughly 60 -years cyclic dT changes suggest that observed rise of dT will level off in the next 5-10 years, when we might expect the lowering of dT by nearly $0.1-0.15^{\circ} \mathrm{C}$ to the end of $2020 \mathrm{~s}$.

\section{ACKNOWLEDGEMENTS}

This work was supported by U.S. National Research Council, Research Associateship Programs, TJ 2114 (Exchange Visitor Program No. P-1-2628). We thank Dr. Gary Sharp (Center for Climate/Ocean Resources Study, Monterey, CA) for revision of the manuscript and useful comments.

\section{REFERENCES}

Bell, G.D., Halpert, M.S., Cosky, V.E., Gelman, M.E., Roplewski, Ch.E., Douglas, A.V., Shnell, R.C. (2000) Climate assessment for 1998. Bull. Am. Meteorol. Soc., 80, pp. 1040-1140.

Brillinger D.R. (1975) Time series. Data analysis and theory. Holt, Rinehart and Winston, Inc., N.Y., Chicago, San Francisco.

Dansgaard, W., Johnsen, S.J., Reeh, N., Gundestrup, N., Clausen, H.B., Hammer, C.U. (1975) Climatic changes, Norsemen and modem man. Nature, 255, pp. 24-28.

IPCC (1990) Climate Change, The IPCC Scientific Assessment. J.T Hougtoon, G.J. Jenkins and J.J. Ephraums( eds). Cambridge University Press, Cambridge, UK, 365 pp.

IPCC (1996) The Science of Climate Change. Contribution of Working Group I to the Second Assessment Report of the Intergovernmental Panel on Climate Change Change [Houghton, J.T., L.G. Meira Filho, B.A. Callander, N. Hams, A. Kattenberg and K.A. Maskell (eds)] Cambridge University Press, Cambridge, UK and New York, NY, USA, 572 pp.

IPCC (2001) Climate Change 2001: The Scientific Basis. Contribution of Working Group I to the Second Assessment Report of the Intergovernmental Panel on Climate Change Change [Houghton, J.T, Y. Ding, D.J. Griggs, M. Noguer, P.J. van der Linden, X. Dai, K. Maskell and C.A. Johnson (eds)]. Cambridge University Press, Cambridge, United Kingdom and New York, NY, USA, $881 \mathrm{pp}$. 
Jones, P.D., Osbom, K.R. Briffa, C.K. Folland, E.B. Norton, L.V. Alexander, D.E. Parker, and N.A. Rainer (2001) Adjusting for sampling density in grid box land and ocean surface temperature time series. J. Geophys. Res., 106, pp. 3371-3380.

Jones, P.D., M. New, D.E. Parker, Martin and I.G. Rigor (1999) Surface air temperature and its changes over the Past 150 years. Rev. Geophys., 37, pp. 173-199.

Lawrimor J., M. Halpert, J. Bell, M. Menne, B. Lyon, R. Schnell, K. Gleason, Easterling, W. Thiaw, W. Wright, R. Heim Jr.,D. Robinson, L. Alexander (2001) Climate Assessment. Bull. Amer. Meteorol. Soc., 82, No. 6, pp. 1304-1380.

Makarov A.A. (1998) World Energetic and Euro-Asian Energetic Space, "Energyatomizdat" 280 pp. (in Russian).

Marple S.L.(Jr.) (1987) Digital spectral analysis with applications, Prentice-Hall, Inc., Englewood Cliffs, New Jersey.

Schneider S.H., Gleick P.H. and L.O. Meams (1990) Prospects for Climate Change. In: RE. Waggoner (ed) Climate Change and U.S. Water Resources, pp. 41-73, John Wiley, New York.

Schneider S.H. (1992) The Climatic Response to Greenhouse Gases. In : RI. Woodward (ed) Global Climate Change. The Ecological Consequences, pp. 1-33. Academic Press, Hartcourt Brace \& Company Publ., London, San Diego, New York, Tokyo.

Sonechkin, D. M. (1998) Climate dynamics as a non-linear Brownian motion. International Journal of Bifurcation and Chaos, 8, pp. 799-803.

\section{ABOUT THE AUTHORS}

Leonid B. Klyashtorin (Doctor of Sciences in Marine Biology \& Fisheries) was born 1934. Since 1958-1965 he worked in Institute Oceanology Ac. Sci. Russia) on the Primary Productivity of the Ocean. Since 1968 up to now he works in Federal Institute for Fisheries and Oceanography (VNIRO): 1968-1980, Research on of Marine and Fresh- Water Fish Respiration. 1980-1990- Research on Salmon Ranching and Natural Salmon Stock dynamics. Since 1990 up to now: Research on the relations between Climate and Long-Term Fish Stock dynamics. Published 120 papers in scientific journals. Main recent publications: 1998, "Long-term climate change and main commercial fish production in the Pacific and Atlantic" Fisheries Research, vol.37, 115-125; 2001, Climate change and long term fluctuations of commercial catches: the possibility of forecasting. FAO Fisheries Technical Paper No 410, pp 86

Alexey A. Lyubushin (Doctor of Sciences in geophysics) was born 1954. He graduated from the Moscow Physical Technical Institute. Since 1984 up to now he is working in the Institute of Physics of the Earth, Ac. Sci., Russia and since 1994 - also in the International Institute of Earthquake Prediction Theory and Mathematical Geophysics, Ac.Sc. Russia). He is a professor of Moscow State Geological Prospecting Academy, Department of High Mathematics and Mathematical Modeling. Research interests: multidimensional signal processing, wavelet analysis, point process statistics, artificial neural networks, geophysical monitoring, earthquake prediction, seismic hazard assessment. Published 75 papers in scientific journals. 